\title{
Evolution of Microstructure, Residual Stress, and Tensile Properties of Mg-Zn-Y-La-Zr Magnesium Alloy Processed by Extrusion
}

\author{
Huseyin Zengin ${ }^{1} \cdot$ Yunus Turen ${ }^{1} \cdot$ Muhammet Emre Turan $^{1} \cdot$ Fatih Aydın $^{1}$ \\ Received: 6 February 2019 / Revised: 15 March 2019 / Published online: 9 April 2019 \\ (c) The Chinese Society for Metals (CSM) and Springer-Verlag GmbH Germany, part of Springer Nature 2019
}

\begin{abstract}
The microstructure, texture, residual stress, and tensile properties of $\mathrm{Mg}-6 \mathrm{Zn}-2 \mathrm{Y}-1 \mathrm{La}-0.5 \mathrm{Zr}$ (wt\%) magnesium alloy were investigated before and after extrusion process, which performed at $300{ }^{\circ} \mathrm{C}$ and $400{ }^{\circ} \mathrm{C}$. The microstructural characterizations indicated that the as-cast alloy was comprised of $\alpha-\mathrm{Mg}, \mathrm{Mg}-\mathrm{Zn}, \mathrm{Mg}-\mathrm{Zn}-\mathrm{La}$, and $\mathrm{Mg}-\mathrm{Zn}-\mathrm{Y}$ phases. During homogenization at $400{ }^{\circ} \mathrm{C}$ for $24 \mathrm{~h}$, most of the secondary phases exhibited partial dissolution. Extrusion process led to a remarkable grain refinement due to dynamic recrystallization (DRX). The degree of DRX and the DRXed grain size increased with increasing extrusion temperature. The homogenized alloy did not show a preferential crystallographic orientation, whereas the extruded alloys showed strong basal texture. The extrusion process led to a significant improvement on the compressive residual stress and mechanical properties. The alloy extruded at $300{ }^{\circ} \mathrm{C}$ exhibited the highest basal texture intensity, the compressive residual stress and hardness, and yield and tensile strengths among the studied alloys.
\end{abstract}

Keywords ZK60 $\cdot$ Magnesium alloy $\cdot$ Residual stress $\cdot$ Texture $\cdot$ Mechanical properties $\cdot$ Extrusion

\section{Introduction}

In recent years, efforts to reduce vehicle weights in the transportation sector have gained momentum as fuel savings and reduced emissions are economically and environmentally beneficial $[1,2]$. In this regard, magnesium alloys have become a center of attention because of their uniquely low density as structural metal. However, magnesium alloys have poor strength at ambient and elevated temperatures which may limit their widespread use [2]. Proper addition of alloying elements and various processing routes such as hot extrusion and heat treatment are considered as typical ways to improve the mechanical properties effectively by refining the grain size and modifying the structure, size, and distribution of second-phase particles [3-5].

$\mathrm{Mg}-\mathrm{Zn}-\mathrm{Zr}$ alloy system provides a good combination of ductility and formability. To further improve the strength

Available online at http://link.springer.com/journal/40195

Huseyin Zengin

huseyinzengin@karabuk.edu.tr

1 Department of Metallurgical and Materials Engineering, Karabuk University, Baliklarkayasi Mevkii Demir Celik Kampusu, 78050 Karabük, Turkey of this alloy system, additions of rare earth elements have been extensively made so far since large amount of thermally stable fine intermetallics can form by RE additions [3-9]. Yu et al. [7] showed that $\mathrm{Ce}$ addition to ZK60 alloy resulted in a basal texture weakening and improvement in yield and tensile strengths, whereas it deteriorated ductility. Zhou et al. [8] reported that $\mathrm{Nd}$ and $\mathrm{Y}$ additions to ZK60 alloy gave rise to an improvement in yield and tensile strengths owing to the remarkable grain refining effect during dynamic recrystallization (DRX). Zhang et al. [9] investigated the mechanical and corrosion properties of $\mathrm{Mg}-\mathrm{Y}-\mathrm{Zn}-\mathrm{Zr}$ alloy with a specific $\mathrm{Y} / \mathrm{Zn}$ addition and showed that the mechanical and corrosion properties of the extruded alloys gradually improved as the amount of $\mathrm{Y} / \mathrm{Zn}$ additions increased. Zhang et al. [10] showed that $\mathrm{Ca}-\mathrm{Ce} / \mathrm{La}$ synergistic alloying provided an excellent strengthening effect, more uniform distribution of fine secondary phase, weaker basal texture and accordingly improved ductility in extruded $\mathrm{Mg}-\mathrm{Zn}$ alloy. Fang et al. [11] studied the effect of $\mathrm{Ce} / \mathrm{La}$ addition on mechanical properties of as-cast $\mathrm{Mg}-\mathrm{Zn}-\mathrm{Y}-\mathrm{Zr}$ and reported that increasing amount of $\mathrm{Ce} / \mathrm{La}$ additions up to $3 \mathrm{wt} \%$ gradually refined the grains and increased the amount of second phases. Moreover, an improvement on the yield and tensile strength was obtained with a $1 \mathrm{wt} \% \mathrm{Ce} / \mathrm{La}$ addition above which it showed a decrease. 
Hot forming process of magnesium alloys, i.e., extrusion, rolling and forging, can effectively lead to much more homogenous and finer microstructure and accordingly provide excellent mechanical properties comparing with their cast counterparts. In respect to hot extrusion, in which a variety of magnesium alloy profiles can be produced, several parameters such as extrusion temperature, speed and ratio are crucial since they have a great influence on final microstructure [12, 13]. Park et al. [12] showed that as the extrusion temperature, ratio and speed increased, the degree of DRX and the DRXed grain size increased as well. It has been reported in a recent study [13] that the distribution of DRXed grains became more uniform and the DRXed grain size gradually increased as the extrusion temperature increased from 200 to $400{ }^{\circ} \mathrm{C}$ in $\mathrm{Mg}-3.0 \mathrm{Zn}-1.0 \mathrm{Sn}-0.3 \mathrm{Mn}-0.3 \mathrm{Ca}$ (wt\%) alloy. Considering that a reasonable DRX generally starts at $300{ }^{\circ} \mathrm{C}$ and an excessive grain coarsening occurs above $400{ }^{\circ} \mathrm{C}$, initial extrusion billet temperatures of $300{ }^{\circ} \mathrm{C}$ and $400{ }^{\circ} \mathrm{C}$ were chosen in this work, and such comparison between the properties of the samples was made.

During casting process, homogenization heat treatment, quenching, or hot extrusion at various temperatures, some incompatibilities between different parts and phases in the material such as sharp thermal gradients, non-uniform plastic flow, or phase transformation may induce tensile residual stress [14], which can be detrimental to mechanical and corrosion properties of magnesium alloys [15, 16]. Although residual stress has a significant effect in materials, the studies are quite limited in the literature. Wang et al. [17] recently showed that the residual stress did not uniformly develop through the thickness of the extruded ZK60 alloy, which was compressive on the surface and tensile in the center. Moreover, an anisotropic residual stress was observed, and the residual stress along the extrusion direction was less than that in the cross section.

Numerous studies have focused on investigating the effects of different alloying additions and processing conditions on the microstructure and mechanical properties of various magnesium alloys thus far. However, the relationship between the microstructure and mechanical properties of individual alloys has not been well understood in terms of texture and residual stress developments. Therefore, this study aimed to clarify the influence of processing conditions and microstructure on the residual stress and tensile properties of a particular $\mathrm{Mg}-6 \mathrm{Zn}-2 \mathrm{Y}-1 \mathrm{La}-0.5 \mathrm{Zr}$ alloy.

\section{Experimental}

The experimental alloy of $\mathrm{Mg}-6 \mathrm{Zn}-2 \mathrm{Y}-1 \mathrm{La}-0.5 \mathrm{Zr}$ (wt $\%$ ) was cast by low-pressure die casting (LPDC) method. Pure $\mathrm{Mg}$ ingots (99.9 wt\%) were melted first at $750{ }^{\circ} \mathrm{C}$ under a controlled Ar gas atmosphere. Then, pure Zn (99.9 wt\%),
Mg-30 wt\% Y, Mg-30 wt\% La, and Mg-30 wt\% Zr master alloys were added into the molten $\mathrm{Mg}$. The molten mixture was kept at $750{ }^{\circ} \mathrm{C}$ for $30 \mathrm{~min}$ followed by mechanically stirring for $15 \mathrm{~min}$ to provide compositional homogeneity. At last, the pressure of airtight steel crucible was increased to 2 bar, and the cylindrical steel molds $(\varnothing 34 \times 190 \mathrm{~mm})$ preheated to $250{ }^{\circ} \mathrm{C}$ were filled. The chemical composition of the alloy was determined by wavelength dispersion $\mathrm{X}$-ray fluorescence and is listed in Table 1. The homogenization treatment was performed at $400{ }^{\circ} \mathrm{C}$ for $24 \mathrm{~h}$ followed by water quenching. The homogenized samples were extruded at two initial billet temperatures of $300{ }^{\circ} \mathrm{C}$ and $400{ }^{\circ} \mathrm{C}$ with an extrusion ratio of $16: 1$ and a ram speed of $0.3 \mathrm{~mm} / \mathrm{s}$, followed by air cooling.

Microstructure characterizations were conducted by optical microscope (OM) and scanning electron microscope (SEM) equipped with an energy-dispersive $\mathrm{X}$-ray spectroscope (EDX). Before the microstructural investigations, standard metallographic sample preparation procedure was applied and the samples were etched with a picral solution. The constituent phase analyses were carried out by means of Rigaku Ultima IV $\mathrm{X}$-ray diffractometer (XRD). Texture analyses were conducted by XRD method.

Residual stress measurements were made by XRD and cutting methods. XRD residual stress measurements were performed on the surface of the half radius of the homogenized alloy and the surface parallel to the extrusion direction in the as-extruded alloys. The residual stress of the samples was measured by X-ray diffraction (Rigaku Ultima IV) with $\mathrm{CuK \alpha}$ radiation $(\lambda=1.54 \AA$ ). The diffraction angle of crystal planes (213) $118.44^{\circ}$ was used for measurements. The $\sin ^{2} \psi$ method was used for residual stress characterization. The equation of this method is given below,

$\frac{d_{\phi \psi}-d_{0}}{d_{0}}=\frac{1+v}{E} \sigma_{\phi} \sin ^{2} \psi-\frac{v}{E}\left(\sigma_{11}+\sigma_{22}\right)$,

where $d_{\varphi \psi}$ is the measured spacing of diffracting plane, $d_{0}$ is the lattice spacing, $E$ is elastic modulus, and $\nu$ is Poisson's ratio. The values of $E$ and $\nu$ are kept as $43,000 \mathrm{MPa}$ and 0.3 , respectively. Different angles of $\varphi\left(0^{\circ}\right)$ and $\psi\left(-45^{\circ},-36.5^{\circ}\right.$, $-29^{\circ},-20^{\circ}, 0^{\circ}$ ) was used for measurements. So as to calculate residual stress in samples, the slope of $d_{\varphi \psi}-\sin ^{2} \psi$ plot was used in accordance with Eq. (1). In order to provide the reliability and reproducibility of the results, three measurements were performed for each specimen at the same conditions. After three residual stress measurements, average value was calculated and given with the error bars.

Table 1 Chemical composition of the fabricated alloy

\begin{tabular}{llllll}
\hline Alloy & $\mathrm{Zn}$ & $\mathrm{Zr}$ & $\mathrm{La}$ & $\mathrm{Y}$ & $\mathrm{Mg}$ \\
\hline ZK60-1La-2Y & 6.12 & 0.57 & 1.05 & 2.10 & Bal. \\
\hline
\end{tabular}


For the cutting method, strain gauge with a sensitivity of $0.3 \%$ and resistance of $350 \Omega$ was used. Firstly, surfacepreparing process using chemical solutions was conducted on the middle of the sample surface. Then, strain gauge was glued with custom adhesive. Catalyst was also used to accelerate the adhesive process. Electrical cable was soldered to the strain gauge and resistance $(350 \Omega)$ was controlled by multimeter. Coating material consists of polyurethane was poured on the strain gauge in order to protect from the environmental conditions. After the preparation process, cutting was started perpendicular to the direction of strain gauge. During cutting, the micro-strain values were obtained as a graphic with the help of software program belonging to the data collector device. The difference between an obvious point at the end of the cutting and initial strain was used to calculate the residual stress. For calculation, Hooke's law was applied which is given in Eq. 3.

The samples for tensile test with a diameter of $5 \mathrm{~mm}$ and gauge length of $25 \mathrm{~mm}$ were prepared from the homogenized and extruded alloys according to EN ISO 6892-1 [18]. Tensile tests were performed on a Zwick/Roell Z600 universal testing machine at a strain rate of $1.67 \times 10^{-3} \mathrm{~s}^{-1}$. Each test condition was repeated at least three times.

\section{Results and Discussion}

\subsection{Microstructure}

Figure 1 represents the XRD patterns of the as-cast and as-homogenized alloys. The peaks for the as-cast alloy included $\alpha-\mathrm{Mg}, \mathrm{Mg}-\mathrm{Zn}$, and $\mathrm{Mg}-\mathrm{Zn}-\mathrm{La}$, and three kinds of ternary equilibrium $\mathrm{Mg}-\mathrm{Zn}-\mathrm{Y}$ phases, which were I-phase $\left(\mathrm{Mg}_{3} \mathrm{Zn}_{6} \mathrm{Y}\right)$ with quasicrystal structure, W-phase $\left(\mathrm{Mg}_{3} \mathrm{Zn}_{3} \mathrm{Y}_{2}\right)$ with cubic structure, and $\mathrm{X}$-phase $\left(\mathrm{Mg}_{12} \mathrm{ZnY}\right)$ with LPSO structure [19]. Previous studies [20, 21] reported that the formation of these $\mathrm{Mg}-\mathrm{Zn}-\mathrm{Y}$ ternary phases strongly depended on the ratio of $\mathrm{Y}$ to $\mathrm{Zn}$, and it is agreed that I-phase, W-phase, and X-phase came out in a sequence as the ratio of $\mathrm{Y}$ to $\mathrm{Zn}$ increased. The diffraction peaks of $\mathrm{Mg}-\mathrm{Zn}$ binary phase disappeared in the profile for the as-homogenized alloy since these binary phases were dissolved in the $\alpha-\mathrm{Mg}$ matrix due to their low thermal stability at the homogenization temperature [22]. Mg-Zn-La ternary phases also showed a partial dissolution during homogenization. However, the diffraction peaks for the I-phase and $\mathrm{W}$-phase remained almost intact while these for the X-phase slightly diminished after homogenization.

The optical and SEM micrographs of the as-cast and as-homogenized ZK60-1La-2Y alloy are shown in Fig. 2. Figure $2 \mathrm{a}$, c shows that the as-cast microstructure was comprised of primary $\alpha-\mathrm{Mg}$ grains $(\sim 50 \mu \mathrm{m})$ and secondphase particles which mainly dispersed on grain boundaries

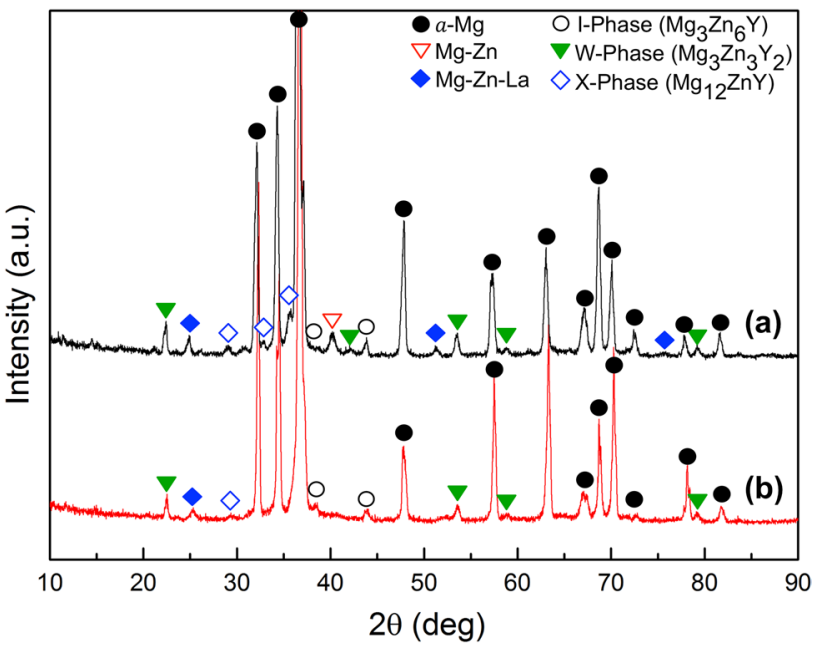

Fig. 1 XRD patterns of the ZK60-1La-2Y alloy: $a$ as-cast and $b$ ashomogenized

showing a semicontinuous network structure and a few inside the grains. As comparing the average $\alpha-\mathrm{Mg}$ grain size of the as-cast ZK60-1La-2Y alloy to that of the ZK60-1La alloy with no $\mathrm{Y}$ addition $(\sim 86.5 \mu \mathrm{m})$, which we reported in our previous study [23], $2 \mathrm{wt} \% \mathrm{Y}$ addition efficiently reduced the $\alpha-\mathrm{Mg}$ grain size due to the combined effect of $\mathrm{Y}$ and $\mathrm{La}$ atom enrichments at the solid-liquid interface during solidification, which resulted in an increase in the nucleation rate and a deceleration of dendrite growth [24]. After homogenization at $400{ }^{\circ} \mathrm{C}$ for $24 \mathrm{~h}$, a slight increase in the $\alpha-\mathrm{Mg}$ grain size by $\sim 3 \%$ and dissolution of second phases by $\sim 40 \%$ are shown in Fig. $2 b$, d. It is also worth mentioning that the ordered distribution of second phases in the as-cast alloy generating a semicontinuous network was disrupted as a result of the dissolution during homogenization resulting in a somewhat discontinuous network structure of discrete second phases as shown in Fig. 2d. The corresponding EDX analyses of the coarse second phases located at triple junctions, denoted as $\mathrm{A}$ in the both as-cast and as-homogenized alloys revealed that these phases were rich in $\mathrm{Mg}, \mathrm{Zn}$, and $\mathrm{Y}$, and their atomic ratio was close to that of W-phase $\left(\mathrm{Mg}_{3} \mathrm{Zn}_{3} \mathrm{Y}_{2}\right)$. In the as-cast alloy, a short rod-like second phase marked with B in Fig. 2c was found to be composed of majorly $\mathrm{Zn}$ and $\mathrm{Zr}$ elements, indicating that the formation of $\mathrm{Zn}-\mathrm{Zr}$ intermetallics also occurred in the ZK60-1La-2Y alloy. It was reported that $\mathrm{Zn}-\mathrm{Zr}$ phase particles can form when $\mathrm{Zn}$ content is above $4 \mathrm{wt} \%$ in $\mathrm{Mg}-\mathrm{Zn}-\mathrm{Zr}$ system [25]. In this study, $\mathrm{Zn}-\mathrm{Zr}$ phases were not detected by XRD analyses due to their small fraction and during EDX analysis of the as-homogenized alloys, no $\mathrm{Zn}-\mathrm{Zr}$ phase was observed. However, as reported in the literature [26], Zn-Zr particles have high thermal stability and mostly remain in the microstructure even after homogenization treatments. Therefore, it is thought that the $\mathrm{Zn}-\mathrm{Zr}$ particles found in 

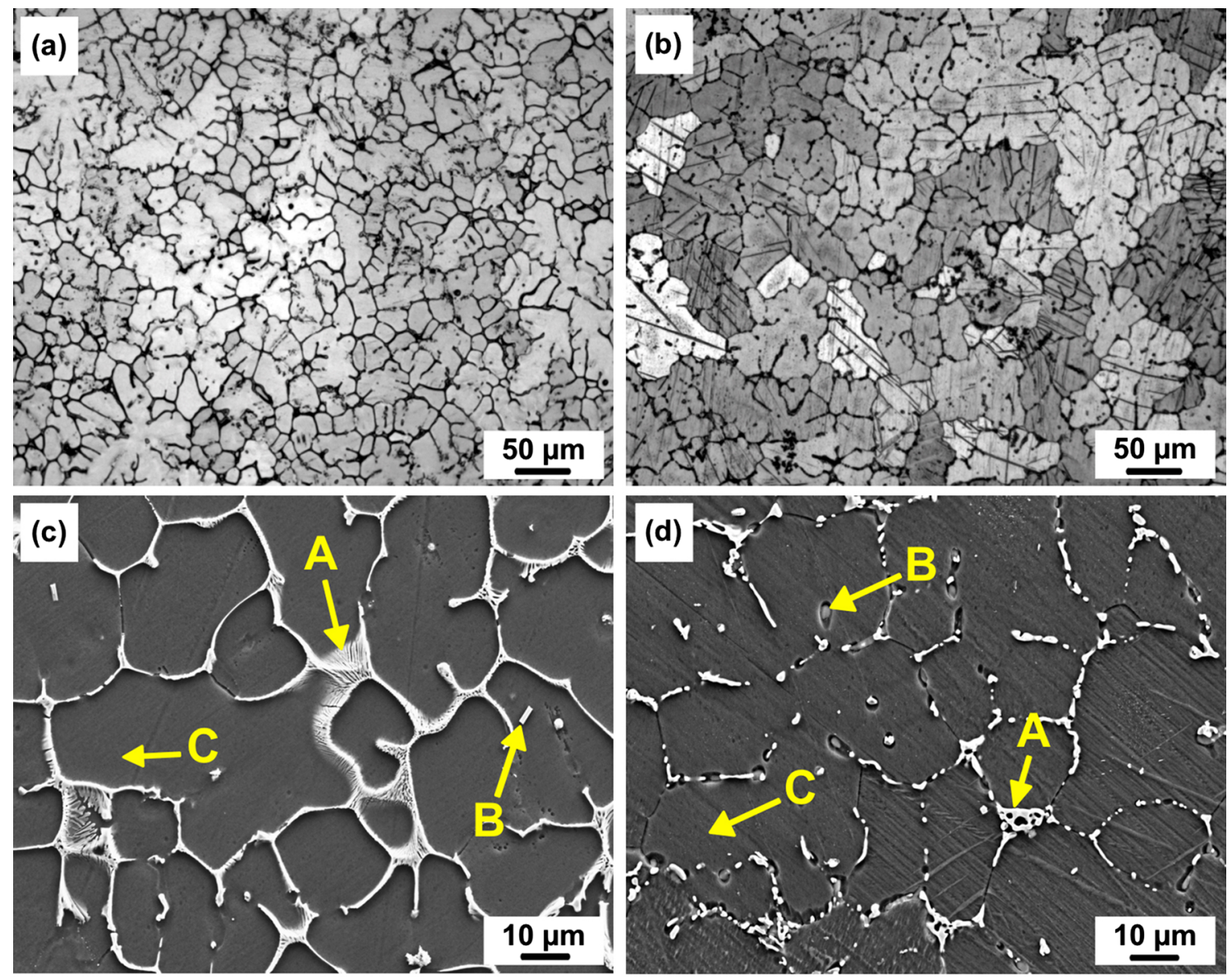

(e)

\begin{tabular}{|c|c|c|c|c|c|c|c|c|c|c|c|}
\hline \multirow{2}{*}{ Condition } & \multirow{2}{*}{ Point } & \multicolumn{2}{|c|}{$\mathrm{Mg}$} & \multicolumn{2}{|c|}{$\mathrm{Zn}$} & \multicolumn{2}{|c|}{$Y$} & \multicolumn{2}{|c|}{ La } & \multicolumn{2}{|c|}{$\mathrm{Zr}$} \\
\hline & & $w t \%$ & at $\%$ & wt\% & at\% & $w t \%$ & at\% & $w t \%$ & at\% & $w t \%$ & at $\%$ \\
\hline \multirow{3}{*}{ As-cast } & A & 17.7 & 40.3 & 41.6 & 35.1 & 37.4 & 23.2 & 2.8 & 1.1 & 0.5 & 0.3 \\
\hline & B & 2.6 & 8.1 & 34.7 & 40.0 & 0.3 & 0.3 & 0.2 & 0.1 & 62.5 & 51.5 \\
\hline & C & 93.8 & 97.6 & 5.3 & 2.1 & 0.4 & 0.1 & 0.2 & 0.1 & 0.3 & 0.1 \\
\hline \multirow{3}{*}{ As-homogenized } & A & 16.7 & 37.9 & 49.8 & 41.9 & 30.2 & 18.7 & 2.3 & 0.9 & 1.0 & 0.6 \\
\hline & B & 45.7 & 73.9 & 33.7 & 20.3 & 0.3 & 0.1 & 20.1 & 5.6 & 0.2 & 0.1 \\
\hline & C & 92.6 & 97.2 & 5.8 & 2.3 & 0.6 & 0.2 & 0.4 & 0.1 & 0.6 & 0.2 \\
\hline
\end{tabular}

Fig. 2 Optical and SEM micrographs of ZK60-1La-2Y alloy: a, $\mathbf{c}$ as-cast, $\mathbf{b}, \mathbf{d}$ as-homogenized, e corresponding EDX results of the points indicated in $\mathbf{c}, \mathbf{d}$

the as-cast state highly likely remained undissolved in the homogenized microstructure in this study. The globularshaped phase designated by B in Fig. 2d contained mostly $\mathrm{Mg}, \mathrm{Zn}$, and $\mathrm{La}$, confirming the XRD results, which showed that the $\mathrm{Mg}-\mathrm{Zn}-\mathrm{La}$ ternary phases were still present in the microstructure after homogenization. Previous studies also reported the formation of $\mathrm{Mg}-\mathrm{Zn}-\mathrm{La}$ phases and their high thermal stability during homogenization [25-29]. Furthermore, the $\alpha$-Mg matrix phase was enriched with $\mathrm{Zn}, \mathrm{Y}, \mathrm{La}$, and $\mathrm{Zr}$ elements after homogenization treatment due to the dissolution of second phases.

Figure 3 illustrates the EDX mapping analysis of as-cast ZK60-1La-2Y, illustrating the distribution of elements in the given microstructure. The most of the secondary phases were densely enriched with majorly $\mathrm{Zn}$ and $\mathrm{Y}$ elements, showing that most of the second phases were $\mathrm{Mg}-\mathrm{Zn}-\mathrm{Y}$ phases, which is in line with the XRD and EDX analyses. La elements also showed localized enrichments, 

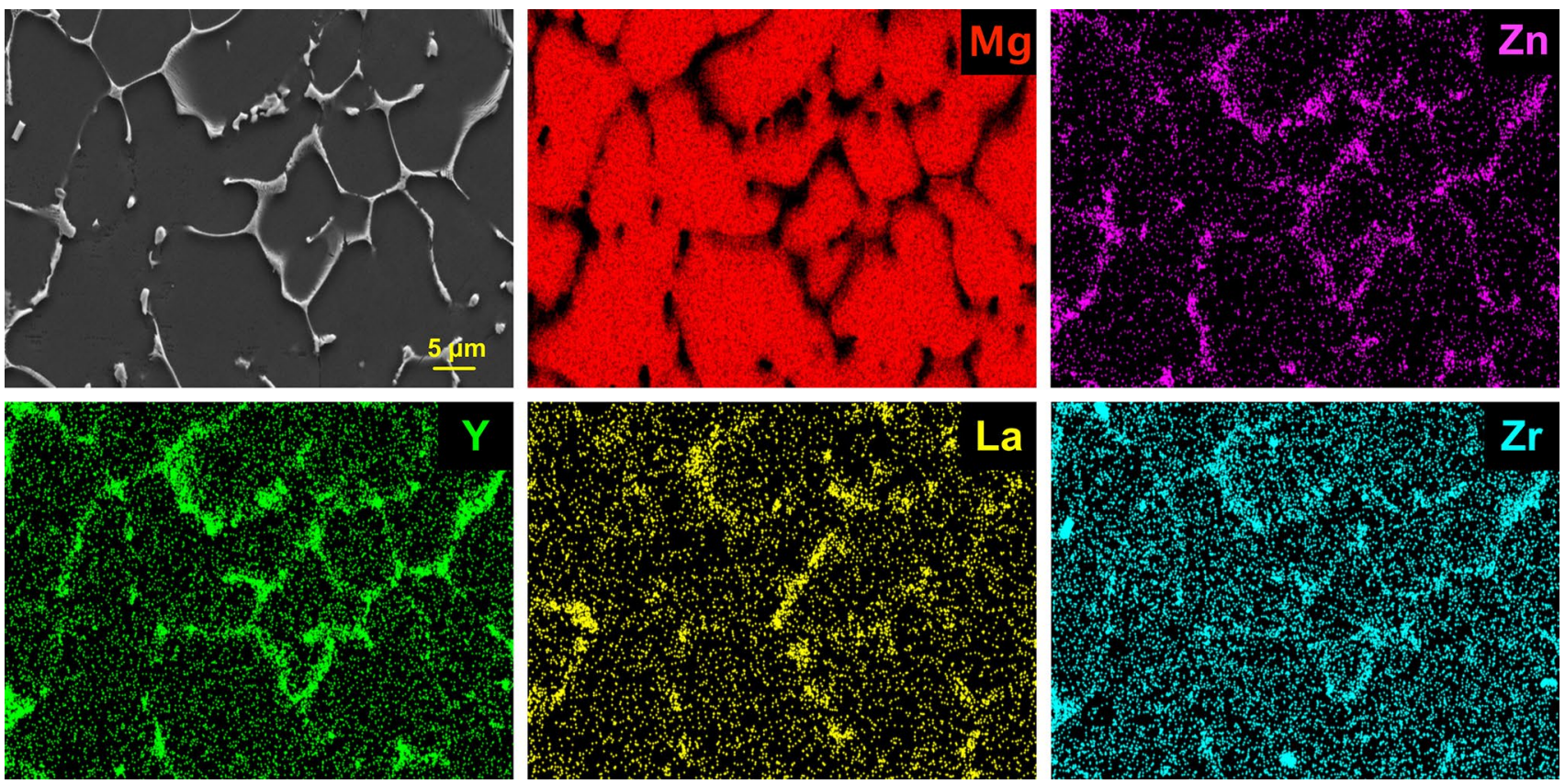

Fig. 3 EDX elemental mappings of the ZK60-1La-2Y alloy

confirming the formation of $\mathrm{Mg}-\mathrm{Zn}-\mathrm{La}$ phase. Furthermore, $\mathrm{Zr}$ elements were seen uniformly in the $\alpha-\mathrm{Mg}$ matrix and intensified at the $\mathrm{Zn}-\mathrm{Zr}$ and other ternary phases.

Figure 4 shows the optical and SEM micrographs of the extruded alloys, taken from the surface, parallel to the extrusion direction. Compared to as-cast and as-homogenized microstructures, extrusion process gave rise to a remarkable grain refining effect because of the DRX mechanism and alignment of second-phase particles along the extrusion direction. The alloy extruded at $300{ }^{\circ} \mathrm{C}$ showed a bimodal grain distribution composed of very fine DRXed grains $(2.3 \mu \mathrm{m})$ and coarse elongated unDRXed grains. The volume fraction of DRXed grains, also expressed as the degree of DRX, was $85 \%$ in the alloy extruded at $300{ }^{\circ} \mathrm{C}$. However, after extrusion at $400{ }^{\circ} \mathrm{C}$, the degree of DRX increased to $95 \%$. The extrusion temperature also appeared to have a big influence on final DRXed grain size, in which it increased from $2.3 \mu \mathrm{m}$ to $3.5 \mu \mathrm{m}$ as the extrusion temperature increased to $400{ }^{\circ} \mathrm{C}$. The relationship between extrusion temperature and DRX mechanism has been extensively studied thus far [12, 13, 30, 31]. Ross et al. [30] showed that both DRX fraction and DRXed grain size increased with increasing extrusion temperature. Shahzad and Wagner [31] reported that extrusion temperature affected the degree of DRX and the activation of plastic deformation modes. At low extrusion temperatures, new grains nucleated at the twin interfaces, and this led to finer DRXed grains, while at higher extrusion temperatures, new grains nucleated at the original grain boundaries. Zener-Hollomon parameter $(Z)$ represents the combination of deformation temperature and strain rate which defined as:

$Z=\dot{\varepsilon} \exp \left(\frac{Q}{R T}\right)$,

where $\dot{\varepsilon}$ is the strain rate, $R$ is gas constant, $Q$ is the activation energy for lattice diffusion, and $T$ is the deformation temperature. In the present study, deformation temperature was the only variable and thus, $Z$ parameter decreased as the extrusion temperature increased according to Eq. (2). It has been reported in several studies that higher values of $Z$ parameter resulted in smaller DRXed grains [29-33]. Therefore, as one might expect, extrusion at $300{ }^{\circ} \mathrm{C}$ resulted in smaller DRXed grains than extrusion at $400^{\circ} \mathrm{C}$.

Secondary phases also influence DRX mechanism during hot deformation [34]. When particle diameter is larger than $1 \mu \mathrm{m}$, the dislocation density and orientation gradient around these particles increase and new grains nucleate at these heterogeneous nucleation sites during extrusion, i.e., particle stimulated nucleation (PSN) $[34,35]$. The second-phase particles smaller than $1 \mu \mathrm{m}$ can act as grain growth inhibitor rather than creating new nucleation sites around them. The size and fraction of the second-phase particles after extrusion at $300{ }^{\circ} \mathrm{C}$ and $400{ }^{\circ} \mathrm{C}$, as shown in Fig. 4c, d, did not change considerably as the extrusion temperature increased, in which most of the fragmented and aligned second-phase particles were larger than $1 \mu \mathrm{m}$, and their volume fractions were about $6.5 \%$ at both extrusion temperatures. However, the relation between $Z$ value 

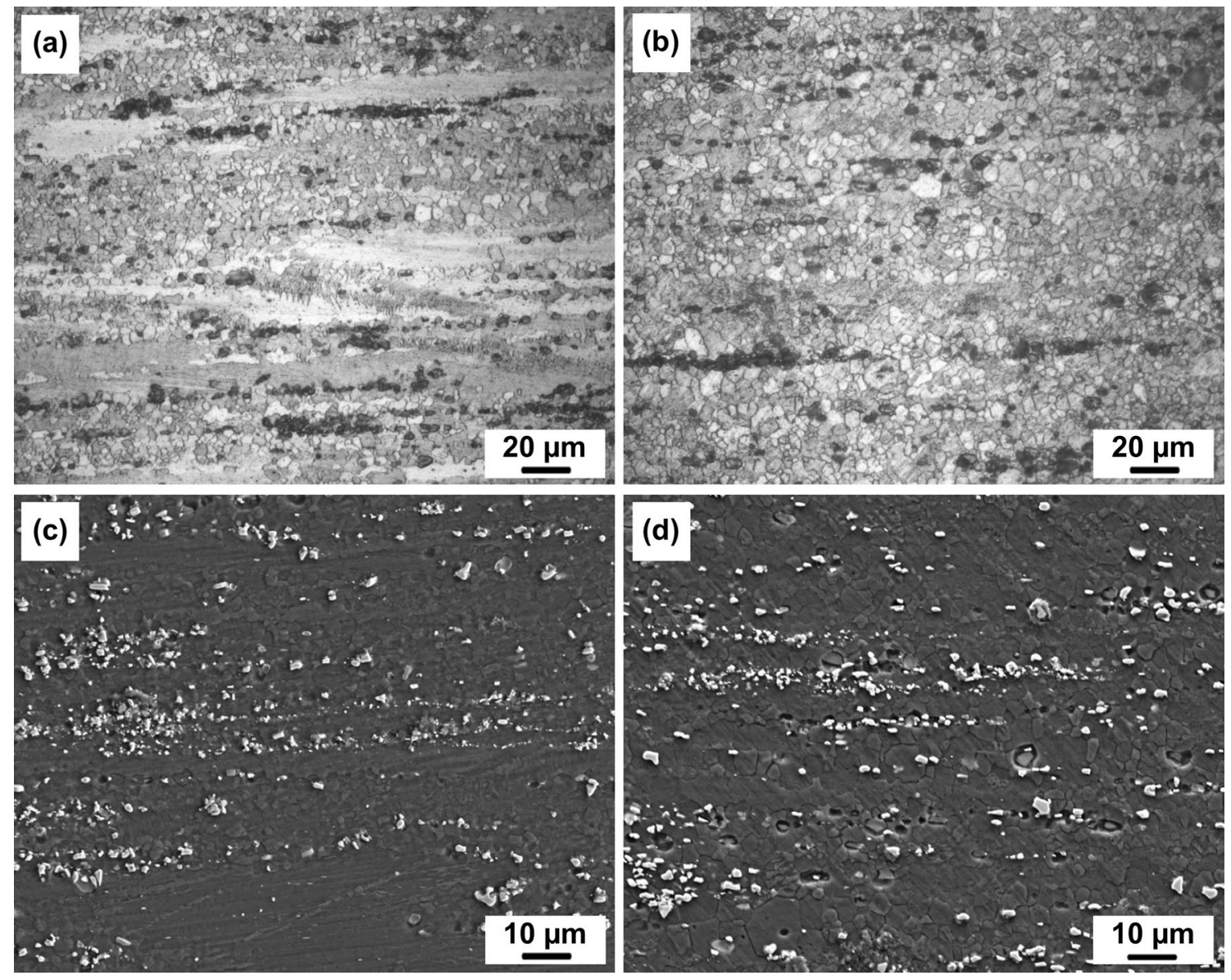

Fig. 4 Optical and SEM micrographs of the as-extruded ZK60-1La-2Y alloy: a, c extruded at $300{ }^{\circ} \mathrm{C}, \mathbf{b}, \mathbf{d}$ extruded at $400{ }^{\circ} \mathrm{C}$

and PSN was described as the likelihood of the occurrence of PSN decreases as the value of $Z$ parameter decreases, i.e., higher extrusion temperatures [34]. Since the size and volume fraction of the secondary phases were found to be similar at both extrusion temperatures in this study, it can be deduced that PSN promoted the DRX more commonly at $300{ }^{\circ} \mathrm{C}$ compared to at $400{ }^{\circ} \mathrm{C}$. As outlined above, at high extrusion temperatures, bulging of original grains occurs and new grains mostly nucleate at the original grain boundaries.

\subsection{Texture}

Figure 5 illustrates the (0002), (1010) and (112̄0) pole figures for the as-homogenized and as-extruded ZK60-1La-2Y alloys at fixed scale to provide a clear comparison. The ashomogenized alloy displayed maximum intensities of 5.9, 7.1, and 5.9 multiples of random distribution for the (0002), $(10 \overline{1} 0)$ and $(11 \overline{2} 0)$ pole figures, respectively. Although the as-homogenized alloy exhibited somewhat strong pole figure intensity values, no preferred crystallographic orientation was observed due to the similarity of intensity values on each plane, indicating that the unit cells were arbitrarily oriented. On the contrary, both extruded alloys showed strong basal texture with high intensity values of 15 and 11 , respectively, demonstrating that (0002) basal planes with $<10 \overline{1} 0>$ directions of most grains aligned with the extrusion direction. This characteristic type of texture frequently observed in extruded magnesium alloys [36]. The (0002) and (112̄0) pole intensities considerably decreased as the extrusion temperature increased, as shown in Fig. 5b, c. It has been shown that unDRXed grains yielded much higher texture intensity than the DRXed grains in extruded magnesium alloys [7, 37]. This indicates that the increased DRX fraction can lead to an effective texture weakening and randomization. As mentioned above, the DRX fraction increased by $10 \%$ with increasing extrusion temperature from to 300 to $400{ }^{\circ} \mathrm{C}$. Thus, such texture weakening at high extrusion temperature was produced by the high fraction of DRXed grains. It should also be noted that PSN can randomize the grain orientation and result in texture weakening [35]. As discussed above, higher $Z$ parameter values, i.e., lower extrusion temperature can lead to more PSN, and thus, a greater texture weakening caused by PSN can be expected in the 


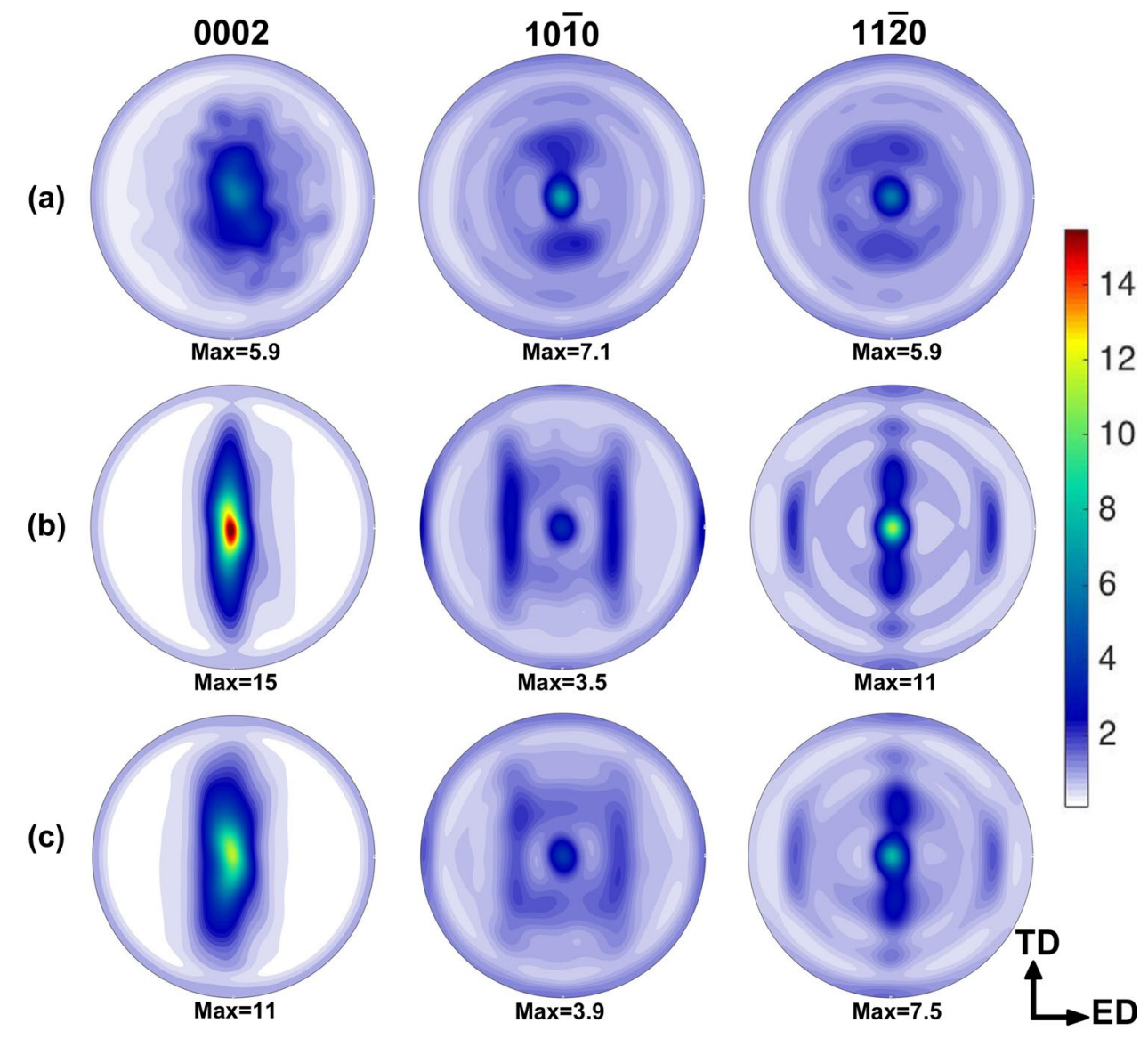

Fig. 5 (0002), (1010) and (112̄0) pole figures of the ZK60-1La-2Y alloy: a as-homogenized, b extruded at $300{ }^{\circ} \mathrm{C}$, $\mathbf{c}$ extruded at $400{ }^{\circ} \mathrm{C}$

alloy extruded at $300{ }^{\circ} \mathrm{C}$. However, considering the pole figure results in Fig. 5, it can be inferred that the improved degree of DRX at $400{ }^{\circ} \mathrm{C}$ predominated over the possible enhanced PSN at $300{ }^{\circ} \mathrm{C}$ in terms of their texture weakening effects. Therefore, lower texture intensity was obtained after extrusion at $400{ }^{\circ} \mathrm{C}$. Although such an assumption is reasonable, further investigations especially on the change in PSN with extrusion temperature in the studied alloys are still needed to provide a detailed explanation.

\subsection{Residual Stress}

Figure 6 shows the $2 \theta$ degree versus $\sin ^{2} \psi$ plot of the investigated samples. There are good linearities which indicate the $\sin ^{2} \psi$ method can be applied during stress measurement for magnesium alloys. Residual stress values were calculated from the plots, and the results are presented in Table 2. The obtained stress values are $-13 \mathrm{MPa},-34 \mathrm{MPa},-26 \mathrm{MPa}$ for as-homogenized,


Fig. $62 \theta$ degree versus $\sin ^{2} \psi$ plot of samples: a as-homogenized, b extruded at $300{ }^{\circ} \mathrm{C}$, $\mathbf{c}$ extruded at $400{ }^{\circ} \mathrm{C}$ 
Table 2 Residual stress measurement results of the samples

\begin{tabular}{lll}
\hline Condition & \multicolumn{2}{l}{ Residual stress $(\mathrm{MPa})$} \\
\cline { 2 - 3 } & XRD method & Cutting method \\
\hline As-homogenized & $-13 \pm 8$ & $-9 \pm 2$ \\
As-extruded $\left(300^{\circ} \mathrm{C}\right)$ & $-34 \pm 11$ & $-71 \pm 10$ \\
As-extruded $\left(400^{\circ} \mathrm{C}\right)$ & $-26 \pm 8$ & $-37 \pm 6$ \\
\hline
\end{tabular}

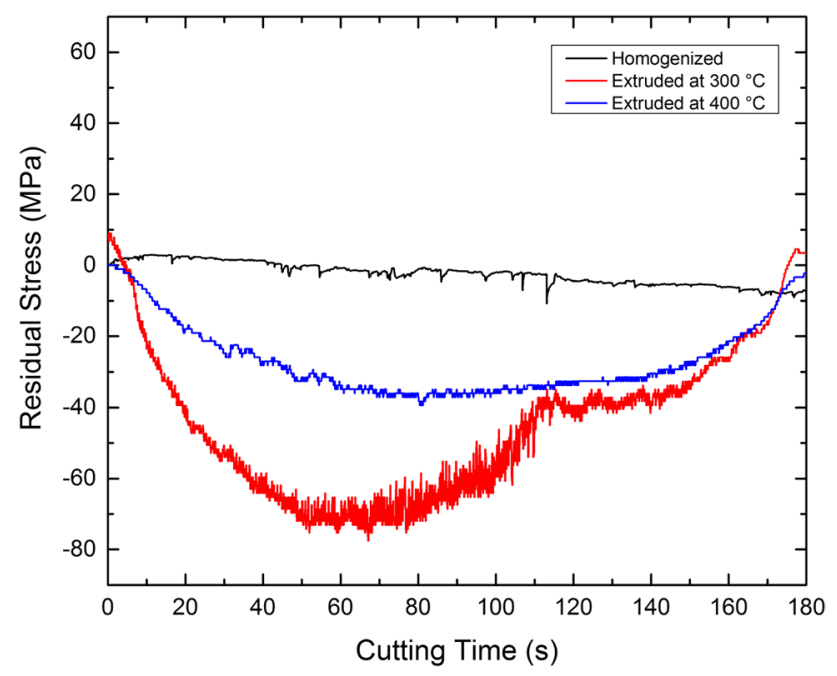

Fig. 7 Trends of residual stress profiles of the studied alloys as function of cutting time

extruded at $300{ }^{\circ} \mathrm{C}$, extruded at $400{ }^{\circ} \mathrm{C}$, respectively. As listed in Table 2, compressive residual stress can be found in all samples. Extrusion process also leads to gain compressive residual stress of the sample [38]. With increasing extrusion temperature, compressive residual stress decreased. The value of residual stress of extruded sample in our study is similar to that of extruded ZK60 alloy conducted by Wang et al. [17]. They reported residual stress of $-20 \mathrm{MPa}$ and $-60 \mathrm{MPa}$ for the extrusion direction (ED) and long-transverse direction (LTD), respectively. Shayegan et al. [38] also studied the residual stress of extruded AZ31B alloy. The extrusion temperature in their study was about $360{ }^{\circ} \mathrm{C}$. They reported a residual stress of -36.6 MPa in extrusion direction. However, nonextruded sample has the lowest residual stress which can be attributed that homogenization treatment gives rise to stress relief.

In addition to the X-ray diffraction residual stress analysis, cutting method using strain gauge was applied in order to investigate stress type and content of specimens as a destructive method. Also, the comparison of stress measurement techniques was evaluated. Figure 7 illustrates the residual stress distribution of the homogenized and extruded samples. Stress values were calculated via Hooke's law after strain values had been collected by software program during cutting. The following formula was used to obtain stress measurement results.

$\sigma_{\text {longitudinal }}=-E \cdot \varepsilon$

where $\sigma_{\text {longitudinal }}$ is the residual stress, $E$ is the elastic modulus of magnesium alloy, and $\varepsilon$ is the difference in strain gauge reading before and after cutting. The maximum stresses during cutting process were calculated as $-9 \mathrm{MPa},-71 \mathrm{MPa},-37 \mathrm{MPa}$ for homogenized, extruded at $300^{\circ} \mathrm{C}$, extruded at $400{ }^{\circ} \mathrm{C}$ samples, respectively, as listed in Table 2. Almost all materials had residual stress at the production stages include especially cooling and forming process. Residual stress values are generally higher in complex shape materials. But produced magnesium alloy in this study did not have any complex shape, so the stress value was lower. The results clearly showed a tendency for having large compressive stresses when hot extrusion process was applied to magnesium alloy. This can be a result of plastic deformation which enhances the non-uniform stress distribution in materials. So, compressive stress was formed during extrusion process. When considering the effect of extrusion temperature, decreasing stress value with an increase in the extrusion temperature was observed according to Fig. 7. It can be attributed to the degree of DRX and the texture formation in the extruded alloys. Since the degree of DRX was lower after extrusion at $300{ }^{\circ} \mathrm{C}$, the dislocation density was most likely higher than the alloy extruded at $400{ }^{\circ} \mathrm{C}$. The high amount of unDRXed grains caused more deformation zones in the materials, so this situation did not allow the deformations to be preferably located and enhanced the compressive residual stress value in the alloy extruded at $300{ }^{\circ} \mathrm{C}$. The higher basal texture intensity in the alloy extruded at $300^{\circ} \mathrm{C}$ also led to an inhibition of basal slip activity, which can result in an improvement in the compressive stress along the extrusion direction. Thus, the high texture intensity also played an important role on the enhancement in the compressive residual stress. As a result, compression residual stress was found in all samples and extrusion process improved the formation of compressive stress. Same trend can also be seen by X-ray diffraction method. So, there has been a consistency between the destructive and nondestructive methods.

\subsection{Mechanical Properties}

The engineering stress-strain curves of the as-homogenized and as-extruded alloys obtained from tensile tests are demonstrated in Fig. 8. The hardness and tensile properties of the alloys are also given in Table 3. The ashomogenized alloy exhibited poor strength and elongation. The extrusion process resulted in a significant improvement on the mechanical properties. The elongation, yield, and tensile strengths were increased by $100 \%, 108 \%$, and 


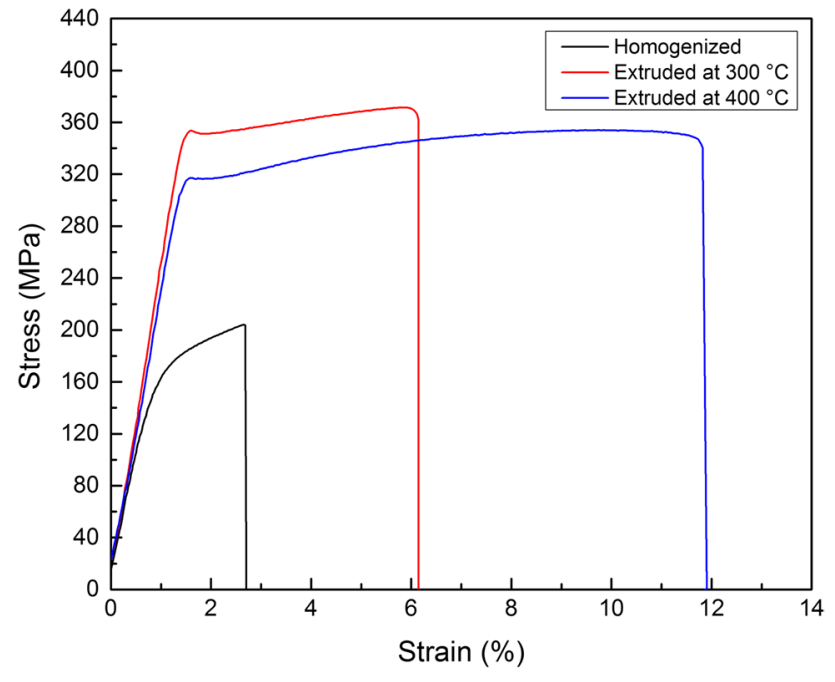

Fig. 8 Stress-strain curves of the ZK60-1La-2Y alloys

$84 \%$, respectively, after extrusion at $300{ }^{\circ} \mathrm{C}$. The alloy extruded at $400{ }^{\circ} \mathrm{C}$ exhibited much higher elongation, whereas the yield and tensile strengths were inferior to its counterpart extruded at $300{ }^{\circ} \mathrm{C}$. The change in the mechanical properties with different processing conditions can be explained by several mechanisms. As shown in Fig. 4, extrusion process resulted in microstructures with very fine dynamically recrystallized grains together with fragmented particles aligned along the extrusion direction. According to Hall-Petch theory [39, 40], a decline in grain size enhances the yield strength since the increased grain boundaries oppose the dislocation motion during plastic deformation. Therefore, such improvement on mechanical properties by extrusion was predominantly ascribed to the grain boundary strengthening. Furthermore, the change in the mechanical properties by extrusion temperature can also be explained by the microstructural differences between the extruded alloys at $300{ }^{\circ} \mathrm{C}$ and $400{ }^{\circ} \mathrm{C}$. As shown in Fig. 4, the extrusion at $300{ }^{\circ} \mathrm{C}$ generated more deformed microstructure than that at $400{ }^{\circ} \mathrm{C}$, displaying a bimodal grain distribution, which consisted of fine DRXed grains and large deformed unDRXed grains. These deformed grains exhibit more work hardened microstructure and accordingly higher dislocation densities [41,
42]. Besides, it was reported that the deformed unDRXed grains contained more $\{10 \overline{1} 1\}-\{10 \overline{1} 2\}$ double twinning than the DRXed grains, and these double twins can act as crack initiation sites and deteriorate the ductility of magnesium alloys as the tensile test direction is parallel to the extrusion direction [43]. Therefore, the alloy extruded at $300{ }^{\circ} \mathrm{C}$ showed higher strength but lower ductility than the alloy extruded at $400{ }^{\circ} \mathrm{C}$.

Unidirectional orientation of second-phase particles can be beneficial for the strength when the sample for tensile test is taken from the surface parallel to the extrusion direction. This means the fragmented and finely oriented second-phase particles can also supply an improvement in strength by more effective dispersive strengthening compared to the coarse secondary phases in the ashomogenized alloys, which can cause premature crack initiation sites and decrease ductility. Furthermore, it was reported that dynamic precipitation of $\mathrm{Mg}-\mathrm{Zn}-\mathrm{Ce}$ particles occurred during extrusion and improved the strength in Ce-containing ZK60 alloy [7]. Thus, in this work, such $\mathrm{Mg}-\mathrm{Zn}-\mathrm{La}$ or $\mathrm{Mg}-\mathrm{Zn}-\mathrm{Y}$ particles might have dynamically precipitated during extrusion and contributed to the increase in overall strength after extrusion process. However, further investigations are needed to verify the positive effect of dynamic precipitation on mechanical properties of the studied alloys.

The texture intensity is another factor that can strongly affect the final mechanical properties of magnesium alloys. This is because the preferential orientation of grains can significantly influence the slip and twinning systems [44, 45]. Kleiner and Uggowitzer [45] reported that when the tensile direction was parallel to the extrusion direction, the activation of (0002) basal slip and pyramidal $\{10 \overline{1} 2\}$ twinning are inhibited, resulting in a higher yield strength. As shown in Fig. 5, the basal texture intensity remarkably increased after extrusion, and thus the yield and tensile strengths were improved by texture strengthening. Furthermore, the improved elongation and deteriorated yield and tensile strength as the extrusion temperature increased from 300 to $400{ }^{\circ} \mathrm{C}$ was also influenced by the change in the DRXed grain size, the degree of DRX and the basal texture intensity. As mentioned above, with the rise in extrusion temperature, the DRXed grain size and the

Table 3 Microstructure and tensile properties of the as-cast, as-homogenized and as-extruded ZK60-1La-2Y alloys

\begin{tabular}{|c|c|c|c|c|c|}
\hline Condition & Hardness (HV) & $\begin{array}{l}\text { Ultimate tensile } \\
\text { strength (MPa) }\end{array}$ & $\begin{array}{l}\text { Yield strength } \\
(\mathrm{MPa})\end{array}$ & Elongation (\%) & $\begin{array}{l}\text { Work-hardening } \\
\text { response, } \sigma_{\mathrm{UTS}}-\sigma_{\mathrm{YS}} \\
(\mathrm{MPa})\end{array}$ \\
\hline As-homogenized & $70 \pm 2$ & $202 \pm 3$ & $170 \pm 3$ & $3 \pm 1$ & 32 \\
\hline As-extruded $\left(300^{\circ} \mathrm{C}\right)$ & $77 \pm 1$ & $371 \pm 4$ & $353 \pm 3$ & $6 \pm 1$ & 18 \\
\hline As-extruded $\left(400^{\circ} \mathrm{C}\right)$ & $73 \pm 2$ & $354 \pm 3$ & $317 \pm 2$ & $12 \pm 2$ & 37 \\
\hline
\end{tabular}


degree of DRX increased. The increase in DRXed grain size resulted in a decrease in the mechanical properties in accordance with the Hall-Petch relation and the higher degree of DRX retained less degree of work hardening, leading to an increase in the elongation but a deterioration in the strength. In connection with this, as presented in Table 3, a higher work-hardening response was obtained at high extrusion temperatures due to the presence of less retained work hardened microstructure. Moreover, as the extrusion temperature increased, the basal texture intensity reduced, which can lead to a ductility enhancement but a strength deterioration [46]. In addition, a recent study revealed that different (0002) distributions in Mg alloys had a significant influence on Hall-Petch slope $(k)$ for twinning and slip even in the same grain size range [47]. They showed that the plate AZ31 alloy which had higher basal texture intensity than the rod AZ31 alloy exhibited the much higher $k$ for slip during tensile test. This indicates that the alloy with higher basal texture can be more sensitive to the hardening by grain refinement. Therefore, in the current study, the smaller DRXed grains in the alloy extruded $300{ }^{\circ} \mathrm{C}$ might have contributed to the increase in the strength of the alloy more efficiently than the alloy extruded at $400{ }^{\circ} \mathrm{C}$.

Residual stress is known as an important finding to predict mechanical performance of produced materials. If sample has tensile residual stress, it can lead to premature damage, so it effects of mechanical performance negatively. In the meantime, compressive residual stress can improve the fatigue life and mechanical strength [48]. In this study, compressive residual stress is observed for samples and especially this stress is obvious for extruded samples according to the measurement results. Extruded at $300^{\circ} \mathrm{C}$ has the highest compressive residual stress among the samples and also it shows the best mechanical performance when tensile and hardness results are considered. So, it can be deduced that there is good relationship between residual stress analysis and mechanical investigations.

\subsection{Conclusions}

The $\mathrm{Mg}-6 \mathrm{Zn}-2 \mathrm{Y}-1 \mathrm{La}-0.5 \mathrm{Zr}$ (wt\%) alloy was successfully cast by LPDC and extruded at low and high temperatures. The evolution of microstructure, texture, residual stress, and mechanical properties was reported. Following conclusions can be drawn:

1. In the as-cast alloy, $\alpha-\mathrm{Mg}, \mathrm{Mg}-\mathrm{Zn}, \mathrm{Mg}-\mathrm{Zn}-\mathrm{La}$ and $\mathrm{Mg}-$ $\mathrm{Zn}-\mathrm{Y}$ phases identified as I-phase $\left(\mathrm{Mg}_{3} \mathrm{Zn}_{6} \mathrm{Y}\right)$, W-phase $\left(\mathrm{Mg}_{3} \mathrm{Zn}_{3} \mathrm{Y}_{2}\right)$, and $\mathrm{X}$-phase $\left(\mathrm{Mg}_{12} \mathrm{ZnY}\right)$ were observed.

2. Homogenization treatment gave rise to a partial dissolution of second phases.
3. A remarkable grain refinement was observed after extrusion process due to the occurrence of DRX. With the rise in the extrusion temperature, the fraction of DRXed grains and DRXed grain size exhibited a considerable increase.

4. The homogenized alloy exhibited a random crystallographic orientation while strong basal texture intensities were found in the extruded alloys along the extrusion direction. The alloy extruded at $300{ }^{\circ} \mathrm{C}$ showed higher basal texture intensity than the alloy extruded at $400{ }^{\circ} \mathrm{C}$ due to the low fraction of DRX.

5. Extrusion process led to an increase on the compressive residual stress. The alloy extruded at $300{ }^{\circ} \mathrm{C}$ had the highest compressive residual stress due to the higher texture intensity and the formation of more deformation zones in the alloy extruded at $300{ }^{\circ} \mathrm{C}$.

6. The mechanical properties of the homogenized alloy were dramatically improved after extrusion. The alloy extruded at $300{ }^{\circ} \mathrm{C}$ exhibited extraordinarily high yield and tensile strengths of 353 and $371 \mathrm{MPa}$, respectively, but lower elongation-to-fracture compared to the alloy extruded at $400{ }^{\circ} \mathrm{C}$. This was attributed to the bimodal distribution of grains, decreased DRXed grain size, decreased degree of DRX, the high basal texture intensity and the high compressive residual stress in the alloy extruded at $300^{\circ} \mathrm{C}$.

Acknowledgements This study is financially supported by the Scientific Research Projects of Karabuk University (KBU-BAP-16/1-DR-075).

\section{References}

[1] M. Kiani, I. Gandikota, M. Rais-Rohani, K. Motoyama, J. Magnes, Alloys 2, 99 (2014)

[2] M. Bamberger, G. Dehm, Annu. Rev. Mater. Res. 38, 505 (2008)

[3] L.L. Rokhlin, Magnesium Alloys Containing Rare Earth Metals: Structure and Properties (CRC Press, Boca Raton, 2003)

[4] Q.S. Yang, B. Jiang, Z.J. Yu, Q.W. Dai, S.Q. Luo, Acta Metall. Sin (Engl. Lett.) 28, 1257 (2015)

[5] T. Tu, X.H. Chen, J. Chen, C.Y. Zhao, F.S. Pan, Acta Metall. Sin. (Engl. Lett.) 32, 23 (2019)

[6] C. Ma, M. Liu, G. Wu, W. Ding, Y. Zhu, Mater. Sci. Eng. A 349, 207 (2003)

[7] H. Yu, Y.M. Kim, B.S. You, H.S. Yu, S.H. Park, Mater. Sci. Eng. A 559, 798 (2013)

[8] H.T. Zhou, Z.D. Zhang, C.M. Liu, Q.W. Wang, Mater. Sci. Eng. A 445-446, 1 (2007)

[9] Z. Zhang, X. Liu, W. Hu, J. Li, Q. Le, L. Bao, Z. Zhu, J. Cui, J. Alloys Compd. 624, 116 (2015)

[10] J.B. Zhang, L.B. Tong, C. Xu, Z.H. Jiang, L.R. Cheng, S. Kamado, H.J. Zhang, Mater. Sci. Eng. A 708, 11 (2017)

[11] X. Fang, S. Lü, J. Wang, X. Yang, S. Wu, Mater. Sci. Eng. A 699, 1 (2017)

[12] S.H. Park, B.S. You, R.K. Mishra, A.K. Sachdev, Mater. Sci. Eng. A 598, $396(2014)$ 
[13] X. Lu, G. Zhao, J. Zhou, C. Zhang, L. Chen, S. Tang, J. Alloys Compd. 732, 257 (2018)

[14] P.J. Withers, Rep. Prog. Phys. 70, 2211 (2007)

[15] L. Commin, M. Dumont, R. Rotinat, F. Pierron, J.E. Masse, L. Barrallier, Mater. Sci. Eng. A 551, 288 (2012)

[16] T. Hosaka, S. Yoshihara, I. Amanina, B.J. MacDonald, Procedia Eng. 184, 432 (2017)

[17] C. Wang, T. Luo, J. Zhou, Y. Yang, Mater. Sci. Eng. A 722, 14 (2018)

[18] EN ISO 6892-1, Metallic Materials-Tensile Testing-Part 1: Method of Test at Room Temperature (ISO 6892-1:2009) (European Committee for Standardization, n.d.)

[19] A. Lan, L. Huo, Mater. Sci. Eng. A 651, 646 (2016)

[20] J.Y. Lee, D.H. Kim, H.K. Lim, D.H. Kim, Mater. Lett. 59, 3801 (2005)

[21] S. Luo, A. Tang, F. Pan, K. Song, W. Wang, Trans. Nonferrous Met. Soc. China 21, 795 (2011)

[22] M. Mezbahul-Islam, A.O. Mostafa, M. Medraj, J. Mater. 2014, e704283 (2014)

[23] H. Zengin, Y. Turen, H. Ahlatci, Y. Sun, J. Mater. Eng. Perform. 27, 389 (2018)

[24] L. Liu, X. Chen, F. Pan, Z. Wang, W. Liu, P. Cao, T. Yan, X. Xu, Mater. Sci. Eng. A 644, 247 (2015)

[25] Z.C. Hildebrand, M. Qian, D.H. StJohn, M.T. Frost, in (Minerals, Metals \& Materials Society (TMS), 2004)

[26] J.D. Robson, C. Paa-Rai, Acta Mater. 95, 10 (2015)

[27] H. Zengin, Y. Turen, H. Ahlatci, Y. Sun, I.H. Kara, Key Eng. Mater. 750, 118 (2017)

[28] Y. Du, M. Zheng, X. Qiao, W. Peng, B. Jiang, Mater. Sci. Eng. A 673, 47 (2016)
[29] M.L. Huang, H.X. Li, H. Ding, J.W. Zhao, S.M. Hao, J. Alloys Compd. 612, 479 (2014)

[30] N.G. Ross, M.R. Barnett, A.G. Beer, Mater. Sci. Eng. A 619, 238 (2014)

[31] M. Shahzad, L. Wagner, Mater. Sci. Eng. A 506, 141 (2009)

[32] A.H. Ammouri, G. Kridli, G. Ayoub, R.F. Hamade, J. Mater. Process. Technol. 222, 301 (2015)

[33] C.I. Chang, C.J. Lee, J.C. Huang, Scr. Mater. 51, 509 (2004)

[34] F.J. Humphreys, M. Hatherly, Recrystallization and Related Annealing Phenomena (Elsevier, Amsterdam, 2012)

[35] J.D. Robson, D.T. Henry, B. Davis, Acta Mater. 57, 2739 (2009)

[36] Y.N. Wang, J.C. Huang, Mater. Chem. Phys. 81, 11 (2003)

[37] N. Stanford, M.R. Barnett, Mater. Sci. Eng. A 496, 399 (2008)

[38] G. Shayegan, H. Mahmoudi, R. Ghelichi, J. Villafuerte, J. Wang, M. Guagliano, H. Jahed, Mater. Des. 60, 72 (2014)

[39] N.J. Petch, J. Iron Steel Inst. 174, 25 (1953)

[40] C.H. Caceres, G.E. Mann, J.R. Griffiths, Metall. Mater. Trans. A 42, 1950 (2011)

[41] S.H. Park, H. Yu, J.H. Bae, C.D. Yim, B.S. You, J. Alloys Compd. 545, 139 (2012)

[42] H. Zengin, Y. Turen, Mater. Chem. Phys. 214, 421 (2018)

[43] M.R. Barnett, Mater. Sci. Eng. A 464, 8 (2007)

[44] A. Chapuis, J.H. Driver, Acta Mater. 59, 1986 (2011)

[45] S. Kleiner, P.J. Uggowitzer, Mater. Sci. Eng. A 379, 258 (2004)

[46] J. Bohlen, M.R. Nürnberg, J.W. Senn, D. Letzig, S.R. Agnew, Acta Mater. 55, 2101 (2007)

[47] H. Yu, C. Li, Y. Xin, A. Chapuis, X. Huang, Q. Liu, Acta Mater. 128, 313 (2017)

[48] M.E. Turan, S. Ozcelik, F. Husem, H. Ahlatci, Y. Sun, I. Tozlu, Proc. Inst. Mech. Eng. Part F J. Rail Rapid Transit 232, 589 (2018) 